\title{
Eliza Juraszek
}

Faculty of Law and Administration

Nicolaus Copernicus University, Toruń, Poland

Roberto Esposito, Living Thought. The Origins and Actuality of Italian

Philosophy, Zakiya Hanafi (tr.), Stanford University Press, California 2012, pp. 296, ISBN 9780804781565.

\section{Roberto Esposito's Living Thought. Philosophy and Politics in the "Italian Theory"}

$16 / 2014$

Political Dialogues

Philosophy, as the study of fundamental and mainly general problems, concerns such problems as existence, values, mind, language and, generally speaking, almost every topic within the universe. During different times in history, philosophy and its way of reasoning and approaches were changing towards various topics. The ancient philosophers, for instance, were seeking for the first cause, medieval philosophers were looking for the God and classical philosophers were trying to find out how the mind works or where the epicenter of subject is. What are the main issues of contemporary philosophy? There are three categories to distinguish: culture, technology and politics. Although these topics could have been found in almost every work of modern philosopher, their dominant role emerged just recently in postmodern philosophy. There are many proposals of dealing with the given categories. One of them, however, seems to be remarkably different than the rest and it attracts the attention and curiosity of contemporary intellectualists: 'the Italian theory'.

Roberto Esposito, considered to be one of the most significant contemporary philosophers and interpreters of Italian philosophy, proposed to reconstruct the history and essential features of Italian thought from the $16^{\text {th }}$ century to the present. The main goal of the author's proposal is also the main thesis of the book: to prove that 'the Italian thought' 'is animated by a genealogical vocation generating political, historical, and life paradigms that may revive philosophy's universal ambitions against its current linguistic relativism. ${ }^{\text {' }}$ In other words, Esposito claims that 'the Italian theory' is a source of knowledge that precedes other philosophies in resolving the contemporary issues. The queries the author attempted to answer in the book are: Is there in fact a difference between Italian and non-Italian thought in philosophy? If yes, what makes the difference? Why should we pay more attention to the Italian philosophy? Can we even say about such thing as "the Italian thought'?

In order to answer them, Esposito drowned into historical analysis of 'the Italian theory' and outlined three main

1 S. Franchi, „Living Thought and Living Things On Roberto Esposito's Il Pensiero Vivente", in: ,Res Publica: Revista de Filosofia Política', 29 (2013), 19-33. 
perspectives within described topic. First of them appeared in the late 1980s and was recognised as 'the Italian difference' based on two defects: the linguistic and the historical. The former one referred to the differences in both English and Italian language. The latter one was the result of foreign cultures' influence on the Italian philosophy. It is the reason why 'the Italian thought is said to have demonstrated insufficient theoretical independence and originality.' (p. 2) This approach took its pattern from the style of historical works of the authors such as Giambattista Vico or Benedetto Croce. It means that the Italian philosophy, rather than opening up a new set of problems, is merely a translation of hermeneutic and metaphysical questions inherited by Italians from European thought. In the next perspective, at least for the authors publishing within its scope, 'the Italian theory' changed its attitude from interpretative to anaylitcal, gaining a new role in the process. From this moment, 'the Italian thought' was more concerned with political and social issues than any matter. Within this trend new social paradigms were created. Not all of them were convincing, however, this stage of philosophical creativity prepared Italian scientists to deal with the dynamics of the globalized world. The last perspective emerged closely about 2000 and up until now reflects on the difference between nihilism and biopolitics. Although merging those two concepts is at least peculiar, nothing daunted for Italians. Esposito wrote: "The peculiarity of contemporary Italian thought resides precisely in this unprecedented double vision: a split gaze focused on the most pressing current events [attualita] and at the same time on the dispositifs that come with a long or even ancient history. Nihilism and biopolitics, in the unset- tling, antinomic way they are articulated, are an ecemplary distillation of this principle.' (p. 4) By linking the archaic concept of nihilism with the modern one, or rather, by exposing the archaic onto the present and vice versa, "the Italian theory' connects knowledge and power, nature and history, technology and life. (p. 4) It cuts through the variety of contemporary thoughts and changes them in the process.

What is 'the Italian theory'? Suprisingly, reading the reviewed book does not give a satisfying answer on this field. Neither does the further inquiry onto the topic. As it turns out, 'the Italian theory' is a term proposed by Alessandro Enriquez in the book entitled 'An Italian Theory' and it means 'the philosophy of what is innately Italian'. The statement seems to be rather a tautology than a clear explanation of some vague term. Esposito tried to resolve this conceptual confusion. He focused on the philosophies of such figures as Machiavelli, Dante, Vico, Leopardi, Croce, Gentile, Gramsci, Negri, and Agamben, to present 'the Italian thought' as an alternative to modern rationalistic European philosophy, and as a solution to the confusion in which the linguistic turn of the twentieth century has lead contemporary philosophy. It is then a reader's task to figure out that 'the Italian theory' is not an unique and separate concept. When dealing with it, we need to understand that it is solely 'the Italian $\mathrm{d}$ i f f e $\mathrm{r}$ e $\mathrm{n} \mathrm{c}$ e' contained in the language and the way of philosophical reasoning. The latter depends, in a shortcut, on analysing any set of problems always in the context of historical de- and reconstruction, which places the contemporary 'Italian thought' at the very high theoretical level and makes it very close to the first from previously enlisted perspectives. 
Is there something new that could be possibly drawn from 'the Italian theory'? Unfortunately, the answer is negative. The proposed style of philosophical reasoning in the Italian context seems to be a mix of the analytical tradition, the critical theory (mainly oriented on hermeneutics and German thought), and French deconstruction in its poststructuralist and postmodern variances. Even the proposal for resolving, or rather curing, the contemporary philosopical issues sounds familiar - according to the Italian theory' philosophy is possible only through its negation - a suspiciously similar claim was previosuly postulated by Wittgenstein and Kant. Living Thought has many negative aspects with the most remarkable complaint against it, that the author is an Italian philosopher himself. There is a question rising - how is he able to notice 'the Italian difference' from the inside? Especially the previously mentioned linguistic differences (Esposito is known as an author who does not know English)? Although the author of Living Thought is one of the most influential from currently living philosophers and the scientific valor of the book cannot be denied, the book itself missed its point - the author tried to explain 'the Italian theory' through 'the Italian theory', which raises even more uncertainties and even greater confusion than the term before reading the dissertation. After all, it is undeniably magnificent source of philosophical knowledge, especially about writings of Vico, Bruno and Machiavelli, and also about modern approaches to the contemporary politico-philosophical problems contained in the works of Agamben, Vattimo, Hardt and Negri. Eventually, the book stands as the great point to start with studying the history of Italian philosophy and it opens a field for further analysis of 'the Italian theory', mostly for Western scholars interested into the topic and factual outlining 'the Italian difference'. 